\title{
Sintering behaviour of Al-6061 powder produced by rapid solidification process
}

\author{
A. Arockiasamy*1, R. M. German' ${ }^{2}$, P. Wang ${ }^{1}$, M. F. Horstemeyer ${ }^{1}$, W. Morgan ${ }^{1}$ \\ and S. J. Park ${ }^{1}$
}

Complex aluminium alloy components fabricated by powder metallurgy (P/M) offer the promise of a low cost and high strength-to-weight ratio, which meets the demands of the automotive sector. This paper describes the die compaction and sintering response of an atomised Al-6061 alloy powder containing $\mathrm{Mg}$ and Si produced by rapid solidification. A design of experiments is used involving three levels each of the die compaction pressure, sintering temperature, peak temperature hold time and heating rate. Three trials were used to obtain the optimum press sinter processing conditions. Besides the mechanical properties, phase transformation and microstructure are investigated. Supplemental insight is gained through thermogravimetric analysis, differential scanning calorimetry and SEM with energy dispersive spectroscopy. Analysis of variation is used to quantify the contribution of each design variables to the mechanical properties.

Keywords: Al-6061 powder, Taguchi method, Sintering, Mechanical properties

\section{Introduction}

The demand for the production of automobile components from aluminium alloy powders requires high strength within a net shaping process. An improved alloying capability from rapid solidification provides possibilities for a wider range of alloying levels with the anticipation of exceptional properties. The potential net shape production of automotive components provides a means to lower vehicle weight. Over the past 15 years, the production of aluminium powder metallurgy $(\mathrm{P} / \mathrm{M})$ components has grown from $\sim 1200$ tons to reach more than 25000 tons. $^{1}$

However, there are difficulties when $\mathrm{Al}$ powder is used in $\mathrm{P} / \mathrm{M}$. One problem is the presence of an oxide layer, which completely covers the powder surface with a detriment in both the compressibility and sinterability. Several routes have been explored to circumvent this difficulty. One option is to adjust the microstructure by adding alloying elements as a means of reaching the desired mechanical properties. Alloying elements, such as $\mathrm{Cu}, \mathrm{Mg}, \mathrm{Si}, \mathrm{Cu}, \mathrm{Pb}, \mathrm{Sn}$ and $\mathrm{Sb}$, and reinforcing phases, such as $\mathrm{SiC}, \mathrm{Al}_{2} \mathrm{O}_{3}$ or $\mathrm{B}_{4} \mathrm{C}$, are suitable for changing the microstructure and forming phases that improve the hardening response. ${ }^{1,2}$ For example, the addition of $<1 \mathrm{wt}-\% \mathrm{Mg}$ facilitates the breakup of the surface oxide layer by forming $\mathrm{MgAl}_{2} \mathrm{O}_{4}$ during sintering, giving a sintered density gain with increasing mechanical properties. ${ }^{3,4}$ Increasing the $\mathrm{Mg}$ content up

${ }^{1}$ Center for Advanced Vehicular System, Mississippi State University, 200 Research Boulevard, Starkville, MS 39759, USA

${ }^{2}$ College of Engineering, San Diego State University, 5500 Campanile Drive, San Diego, CA 92182-1326, USA

*Corresponding author, email aanton@cavs.msstate.edu to $3.5 \mathrm{wt}-\%$ in a 7000 series alloy offers even better properties. ${ }^{5}$ In contrast, Lumley reported that alloying with high $\mathrm{Mg}$ contents results in low properties due to the low solubility. ${ }^{6}$ The changes of mechanical property have further been examined in the ternary system containing $\mathrm{Al}, \mathrm{Mg}$ and $\mathrm{Cu}$ with further alloy with $\mathrm{Sn}$ and $\mathrm{Ag} .{ }^{7-10}$ On the other hand, major improvement on sinterability of $\mathrm{Al}$ alloys (primarily $7 \mathrm{xxx}$ and $2 \mathrm{xxx}$ series) containing $\mathrm{Pb}, \mathrm{Sn}$ and $\mathrm{Sb}$ have been achieved through liquid phase sintering. ${ }^{11-16}$ Silicon is one addition that is now commonly used due to several property gains. ${ }^{17}$ To increase the elastic modulus, it is common to incorporate hard ceramic phases such as $\mathrm{SiC}, \mathrm{Al}_{2} \mathrm{O}_{3}$ or $\mathrm{B}_{4} \mathrm{C}$. ${ }^{17}$

This paper uses the Taguchi design of experiments approach to characterise the press sinter response of an Al-6061 alloy powder produced by rapid solidification. The influence of processing parameters, such as die compaction pressure, heating rate, sintering temperature and sintering holding time, is linked to the final density and mechanical properties. Optimum conditions obtained from the Taguchi study were confirmed experimentally. One of the failures of the Taguchi approach is the fact that partial factorial design denies a robust sense of interactions and cause-effect relations. This leads to a confounded understanding. On the one hand, the Taguchi approach economises the experimental labour but with a sacrifice in generating a deep understanding of the root relations.

\section{Experimental}

\section{Powder characterisation}

The powder used in this study was an atomised Al-6061 alloy supplied by Epson-ATMIX. The characteristics of this powder are given in Table 1.

(C) 2010 Institute of Materials, Minerals and Mining

Published by Maney on behalf of the Institute

Received 20 October 2009; accepted

DOI 10.1179/003258909X12573447241626 
Table 1 Powder characterisation of Al-6061 alloy powder

\begin{tabular}{lllll}
\hline Material & Median particle size, $\mu \mathrm{m}$ & Apparent density, $\mathbf{g ~ c m}^{-3}$ & Tap density, $\mathbf{g ~ c m}^{-3}$ & Pycnometer density, $\mathbf{g ~ c m}^{-3}$ \\
\hline Al-6061 & 150 & 0.73 & 1.18 & 2.64 \\
\hline
\end{tabular}

\section{Particle shape}

The powder was subjected to standard SEM analysis after being sputter coated with $\mathrm{Pd} / \mathrm{Au}$ to enable determination of the particle shape.

\section{Thermal analysis}

Differential scanning calorimetry (DSC) experiments were conducted (SetSys Setaram) over the temperature range from 25 to $700^{\circ} \mathrm{C}$ at a constant heating rate of $5^{\circ} \mathrm{C} \mathrm{min}{ }^{-1}$. A baseline correction was applied in two stages. First, the DSC run with an empty $75 \mathrm{~mL}$ crucible was subtracted from the experiment. Second, the data were corrected for drift and heat capacity differences using standards.

\section{Die compaction}

The powder was compacted into transverse rupture bars at 55-550 $\mathrm{MPa}$ with a focus on determining the green density response to compaction pressure. Subsequently, the powder was compressed into tensile bars for further determination of tensile behaviour. No lubricant or binder was mixed with the powder, but Acrawax $\mathrm{C}$ was used as a die wall lubricant to minimise friction and to ease ejection.

\section{Dilatometer}

The densification behaviour of the green sample was studied using vertical push rod dilatometer (Unitherm Model 1161; Anter Corp., Pittsburgh, PA, USA) in pure nitrogen atmosphere. This test was carried out at a constant heating rate of $5^{\circ} \mathrm{C} \mathrm{min}{ }^{-1}$ towards the peak temperature of $800^{\circ} \mathrm{C}$. The dwell time set at the peak was $60 \mathrm{~min}$.

\section{Sintering}

For sintering, a Taguchi parameter design was used as tool for analysis of variance (ANOVA). In the Taguchi parameter design, three sintering temperatures $(610,630$ and $\left.650^{\circ} \mathrm{C}\right)$, three peak temperature hold times $(10,20$ and $30 \mathrm{~min})$ and three heating rates $(1,5$ and $10^{\circ} \mathrm{C} \mathrm{m^{-1 }}$, were applied to compacts pressed at three pressures $(110,330$ and $550 \mathrm{MPa})$ involving low, middle and high values. An orthogonal array exploring the maximum degrees of freedom required for the experimental exploration was employed. ${ }^{18}$ Table 2 shows the layout of the experimental design. Each experiment was conducted with three replications. The ANOVA technique was used to identify the optimum sintering conditions. This can give information about the effect of sintering temperature, heating rate, sintering time and compaction pressure.

\section{Sample characterisation Density}

The Archimedes water immersion method was used for both green and sintered samples.

\section{Hardness}

The hardness was measured using the Vickers hardness scale. The applied load was $200 \mathrm{kgf}$. At least five measurements were made to ensure accuracy.

\section{Tensile test}

A universal compression tension testing machine 5669 was employed at a strain rate of $2 \mathrm{~min}^{-1}$ to evaluate the tensile strength of the sintered compacts. The test specimen has the basic shape of a tensile dog bone, $80 \mathrm{~mm}$ long, with the centre section $5.7 \times 4 \times 31.7 \mathrm{~mm}$ (width $\times$ thickness $\times$ length).

\section{Transverse rupture strength}

A universal compression tension testing machine 5869 was employed at a strain rate of $2 \mathrm{~mm} \mathrm{~min}^{-1}$ to study the transverse rupture strength of sintered $\mathrm{Al}$ compacts.

\section{Microstructure}

Metallographic mounts of the sintered alloy were prepared using standard metallographic techniques. Microstructural characterisation was carried out using a Zeiss Axiovert OM and a Jeol SEM with EDS.

\section{Results and discussion}

\section{Powder characterisation}

\section{Particle shape}

The SEM images of the as received powder are shown in Fig. 1. The powder is predominantly spherical in shape. Micrograins are seen on the particle surface. This microstructure is due to the effect of cooling rate of the molten Al alloy during atomisation. The existence of numerous grain boundaries between micrograins enhances the densification due to an increased grain boundary diffusion contribution to sintering.

\section{Phase transformation}

Atmosphere plays a vital role in determining the mechanical properties of the parts. Dry $\mathrm{N}_{2}$ is the most

Table 2 Experimental layout and factor distribution based on orthogonal array L9

\begin{tabular}{|c|c|c|c|c|}
\hline Experiment ID & Sintering temperature, ${ }^{\circ} \mathrm{C}$ & Hold time, $\min$ & Heating rate, ${ }^{\circ} \mathrm{C} \min ^{-1}$ & Die compaction pressure, $\mathrm{MPa}$ \\
\hline 1 & 610 & 10 & 1 & 550 \\
\hline 2 & 610 & 20 & 10 & 110 \\
\hline 3 & 610 & 30 & 5 & 330 \\
\hline 4 & 630 & 10 & 5 & 330 \\
\hline 5 & 630 & 20 & 10 & 550 \\
\hline 6 & 630 & 30 & 1 & 110 \\
\hline 7 & 650 & 10 & 5 & 110 \\
\hline 8 & 650 & 20 & 1 & 330 \\
\hline 9 & 650 & 30 & 10 & 550 \\
\hline
\end{tabular}




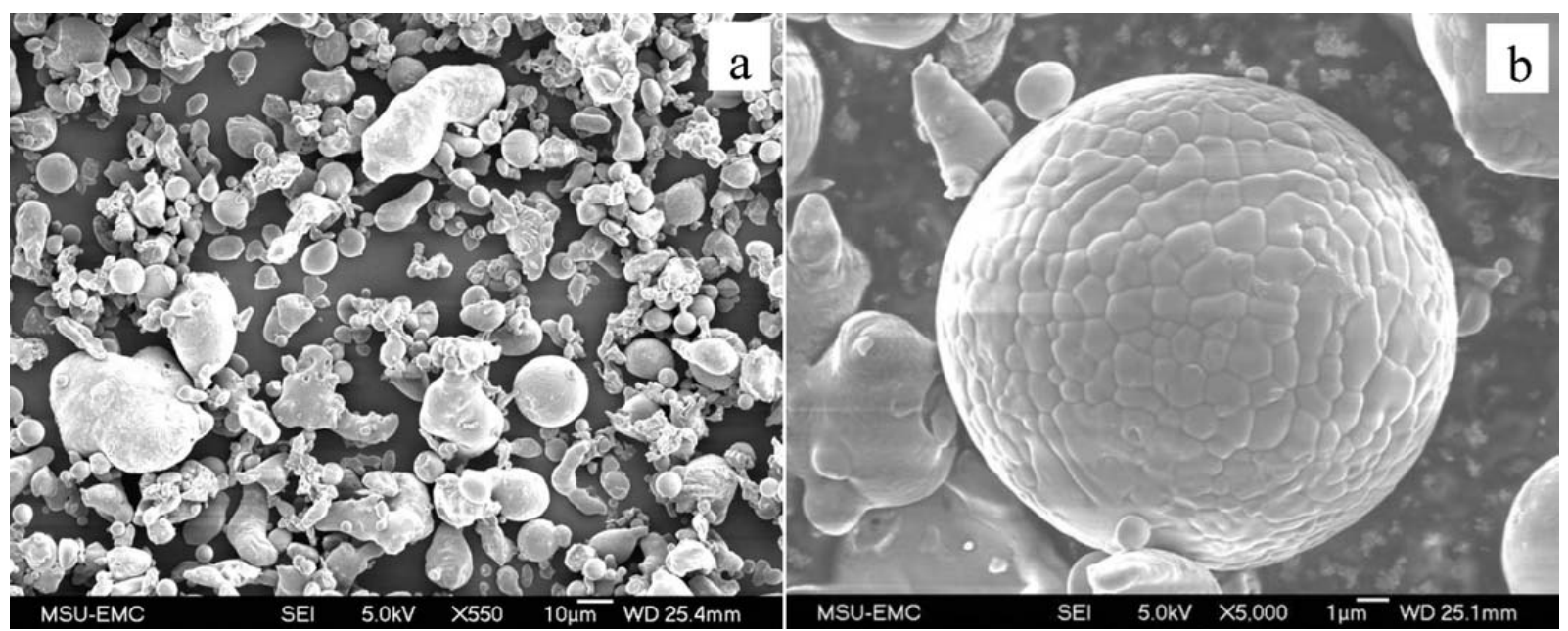

a lower magnification; $b$ higher magnification

1 Images (SEM) of Al-6061 powder
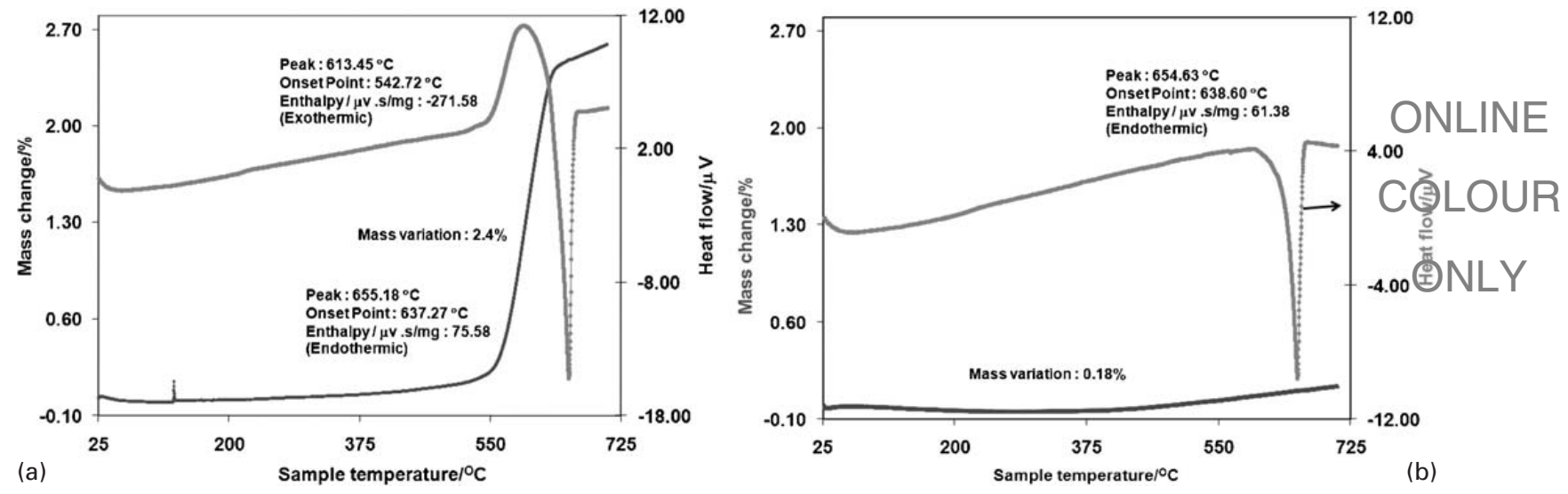

2 Curves (TGA-DSC) for alloy mixture in $a \mathrm{~N}_{2}$ and $b$ Ar atmospheres

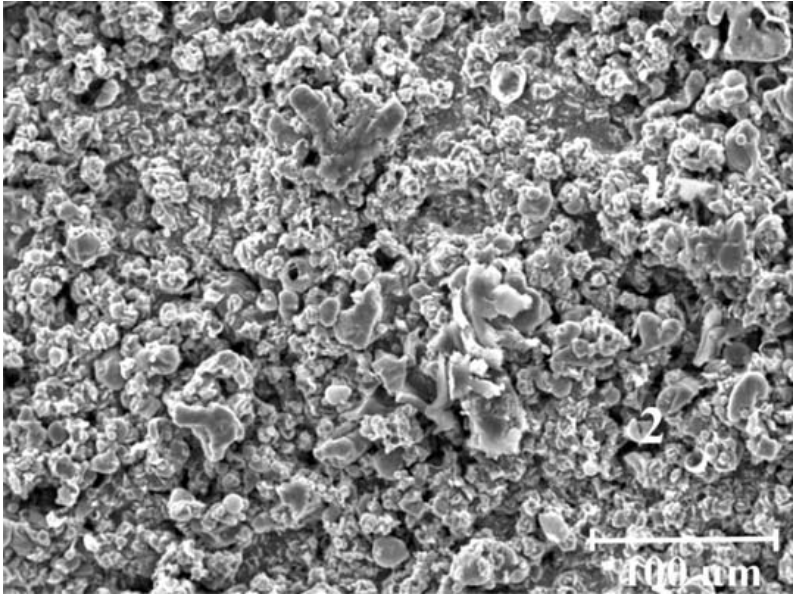

3 Image (SEM) of Al-6061 in $\mathrm{N}_{2}$

common atmosphere for sintering aluminium. ${ }^{20-26}$ Vacuum is more effective than $\mathrm{Ar}$ and $\mathrm{H}_{2}$, which are detrimental to sintered density due to reduction in oxide and generation of $\mathrm{H}_{2} \mathrm{O}$ vapour at high temperatures resulting in pore generation. ${ }^{22,23}$

The thermogravimetric analysis (TGA)-DSC curves for the investigated Al-6061 in $\mathrm{N}_{2}$ and Ar are presented in Fig. 2. These results show that the endothermic peaks originated in the range of $600-665^{\circ} \mathrm{C}$ in $\mathrm{N}_{2}$ and $\mathrm{Ar}$ atmospheres due to melting of Al-6061. This induces supersolidus liquid phase sintering, with obvious densification benefits, but usually with rapid grain growth. In a $\mathrm{N}_{2}$ atmosphere, there is an additional exothermic peak at $593^{\circ} \mathrm{C}$.

Samples collected after the DSC run were analysed by SEM-EDS (Fig. 2). Chemical analysis by EDS was performed in two different locations, and the composition of the phases present revealed the presence of AlN as shown in Fig. 3 and Table 3. From these data, it is inferred that the exothermic peak corresponds to the reaction between $\mathrm{Al}$ and nitrogen to form AlN. There are reports which reveal the existence of AlN in sintered Al alloys containing $\mathrm{Mg}$ when sintered in $\mathrm{N}_{2}{ }^{23,24}$ The formation of AlN may possibly reduce the pressure in the pore spaces relative to the external atmosphere,

Table 3 Results of EDS for Al-6061 in $\mathrm{N}_{2}$

\begin{tabular}{llllllll}
\hline Spectrum & Al, wt-\% & Mg, wt-\% & Si, wt-\% & N, wt.-\% & O, wt-\% & C, wt-\% & Fe, wt-\% \\
\hline Spectrum 1 & 66.3 & 6.4 & 0.5 & 9.2 & 16.4 & 0.0 & 1.1 \\
Spectrum 2 & 20.9 & 1.3 & 0.2 & 16.9 & 13.9 & 46.8 & 0.0 \\
\hline
\end{tabular}




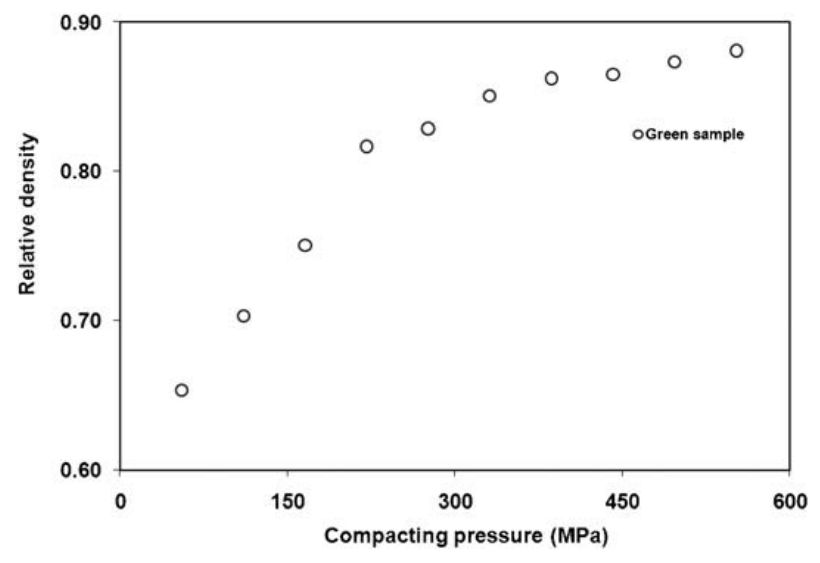

4 Die compaction behaviour of Al-6061 powder: green density $v$. compaction pressure

which induces pore filling at grain sizes. It is suggested that pore filling is an important densification mechanism during sintering of aluminium. Formation of AIN disrupts the oxide on aluminium and facilitates the diffusion processes. ${ }^{20,23}$ Such AlN dispersions increase the mechanical properties such as hardness, tensile strength and wear resistance.

\section{Die compaction behaviour}

Powder compressibility was investigated between 55 and $550 \mathrm{MPa}$. The results are given in Fig. 4 in terms of the green density. At a compacting pressure over $350 \mathrm{MPa}$, the compact exhibited a green density below $85 \%$ of the pycnometer density. A compacting pressure of $550 \mathrm{MPa}$ was selected. Table 4 shows the variation of green, theoretical and sintered densities. These values increase with increasing compaction pressure. This may be attributed to the increase in compaction pressure and how it causes workhardening of the particles. Specimen prepared at the minimum compaction pressure of $55 \mathrm{MPa}$ showed a green density of $1.82 \mathrm{~g} \mathrm{~cm}^{-3}$, while those prepared at $550 \mathrm{MPa}$ showed a green density of $2 \cdot 45 \mathrm{~g} \mathrm{~cm}^{-3}$. For other compaction pressures, the green density was intermediate between these values.

\section{Sintering behaviour}

\section{Dilatometer studies}

The effect of compaction pressure on shrinkage of Al6601 is shown in Fig. 5. Compaction pressure greatly influences the densification of the alloy. Small shrinkage value was obtained for the compacts prepared at low

Table 4 Sintered densities and mechanical properties of Al-6061compacts

\begin{tabular}{|c|c|c|c|c|c|c|c|}
\hline \multirow[b]{3}{*}{ ID } & \multicolumn{4}{|c|}{ Green sample } & \multicolumn{3}{|c|}{ Sintered sample } \\
\hline & \multicolumn{2}{|l|}{ Density } & \multicolumn{2}{|l|}{ Density } & \multirow{2}{*}{$\begin{array}{l}\text { Hardness } \\
\text { HV }\end{array}$} & \multirow{2}{*}{$\begin{array}{l}\text { Elongation } \\
\%\end{array}$} & \multirow{2}{*}{$\frac{\text { UTS }}{\mathrm{MPa}}$} \\
\hline & $\mathrm{g} \mathrm{cm}^{-3}$ & $\%$ & $\mathrm{~g} \mathrm{~cm}^{-3}$ & $\%$ & & & \\
\hline 1 & $2 \cdot 4$ & 91 & $2 \cdot 6$ & 95 & 41 & 9 & 101 \\
\hline 2 & 1.9 & 72 & $2 \cdot 3$ & 80 & 25 & 1 & 32 \\
\hline 3 & $2 \cdot 3$ & 87 & 2.5 & 92 & 32 & 10 & 130 \\
\hline 4 & $2 \cdot 3$ & 87 & $2 \cdot 6$ & 96 & 29 & 6 & 75 \\
\hline 5 & $2 \cdot 4$ & 91 & $2 \cdot 6$ & 96 & 41 & 17 & 107 \\
\hline 6 & 1.9 & 72 & $2 \cdot 0$ & 74 & 22 & 5 & 116 \\
\hline 7 & 1.9 & 72 & $2 \cdot 2$ & 81 & 23 & 7 & 119 \\
\hline 8 & $2 \cdot 3$ & 88 & $2 \cdot 4$ & 89 & 28 & 9 & 127 \\
\hline 9 & $2 \cdot 4$ & 91 & $2 \cdot 6$ & 96 & 39 & 18 & 131 \\
\hline
\end{tabular}

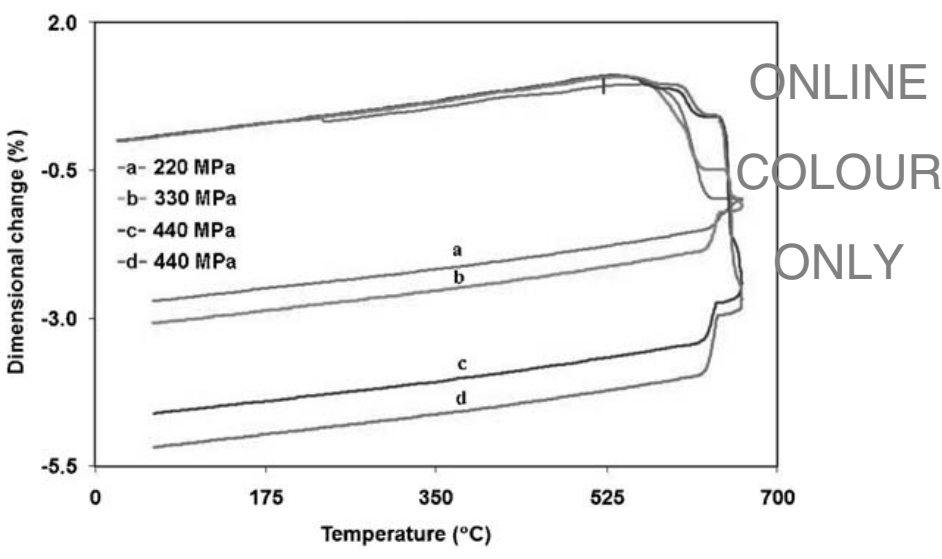

5 Effect of compaction pressure on shrinkage of Al6061 alloy

compaction pressure value of 220 than $550 \mathrm{MPa}$. The shrinkage value was two times higher in the later case, which in turn indicates the densification of the alloy.

\section{ANOVA analysis}

Sintering is the phenomenon in which the material transport driven by surface energy or capillary force is accelerated when they are heated to relatively high temperature. ${ }^{27}$ The net result is the formation of bonds between particles by closing or smoothening of the pore/ solid interface or by a combination of the two phenomena. Consequently, sintering generally involves a loss of surface area and an increase in the strength of the compact. ${ }^{28}$ Sintering process is categorised into activated liquidus and solidus processes. ${ }^{29}$ In this study, the authors' aim was to sinter in the solid state by operating below the melting temperature of the alloy. Table 4 shows the mechanical properties of both green and sintered Al-6061 compacts where UTS denotes the ultimate tensile strength. Figure 6 shows a contribution plot from the design factors based on ANOVA. In Fig. 6, TRS is the transverse rupture stress, which is calculated from the flexure formula, required to break a specimen as a simple beam supported near the ends and applying the load midway between the fixed centrelines of the supports.

\section{Sintering temperature effect}

During high temperature sintering, grain boundary diffusion is active in removing pores, giving more

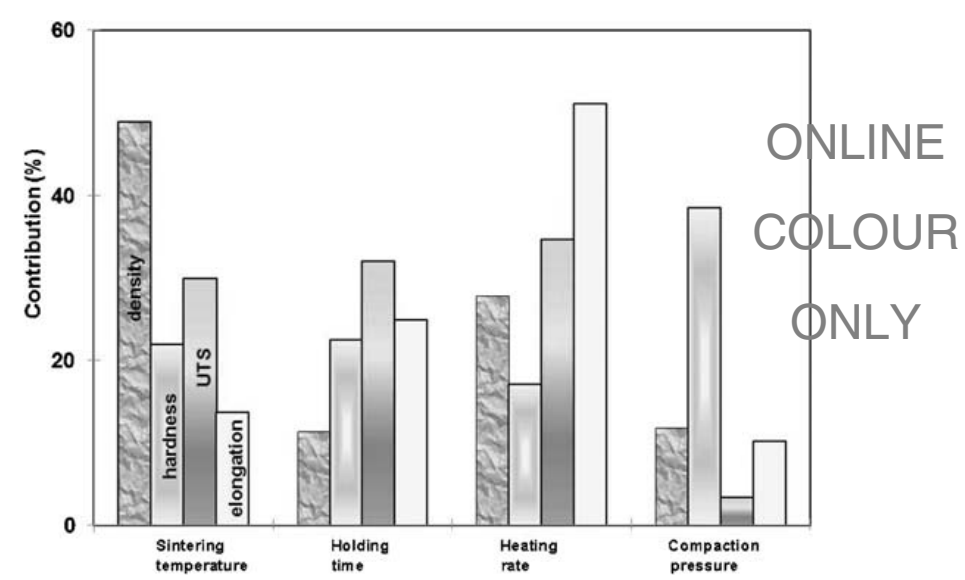

6 Contribution plots of design factors (density, hardness, ultimate tensile strength and elongation) based on ANOVA 


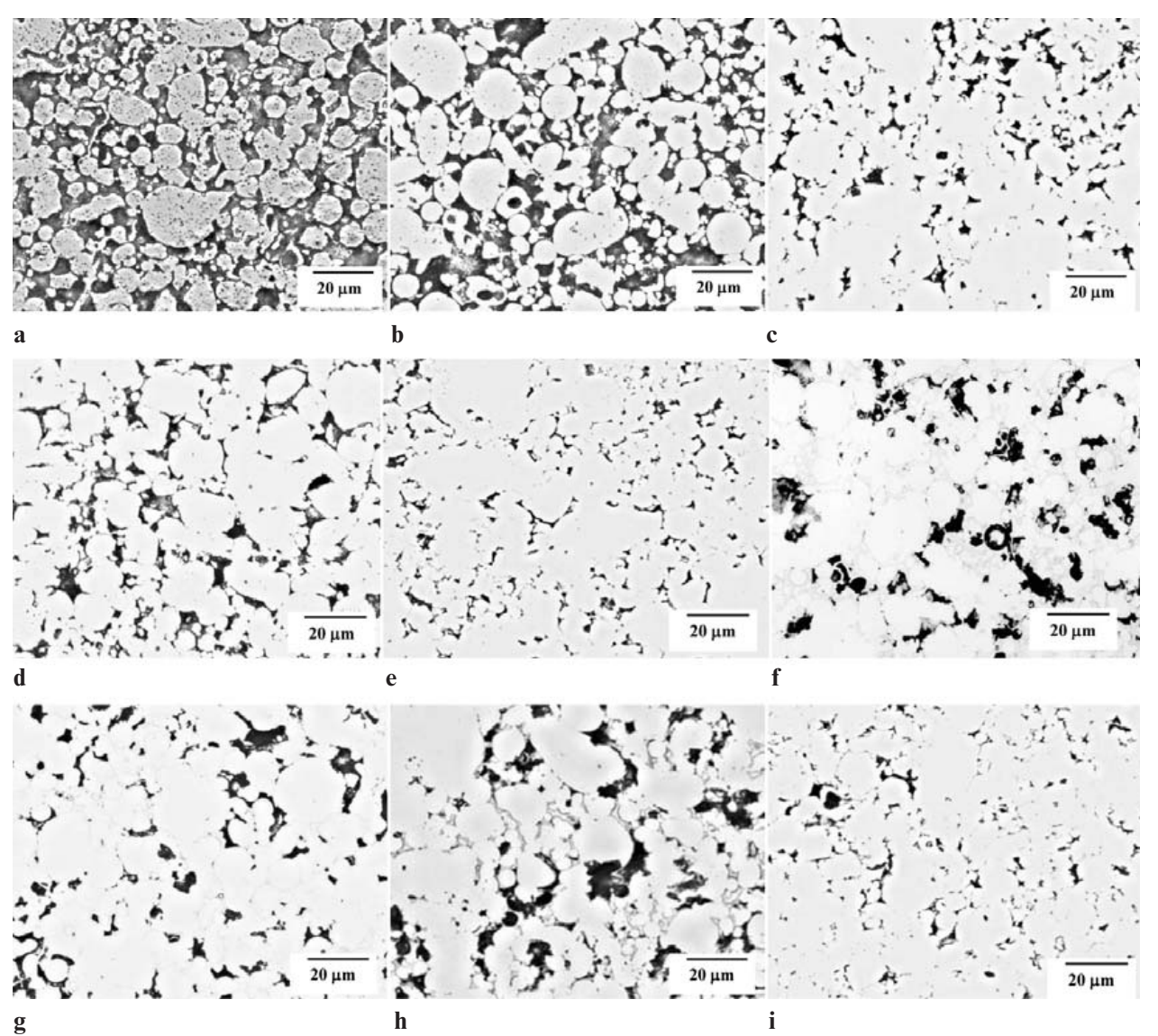

$a$ Experiment $1 ; b$ Experiment $2 ; c$ Experiment $3 ; d$ Experiment $4 ;$ e Experiment $5 ; f$ Experiment $6 ; g$ Experiment 7 ; $h$ Experiment 8; $i$ Experiment 9

7 Microstructure of sintered Al-6061 alloys in $\mathrm{N}_{2}$ atmosphere based on orthogonal array

densification. However, the most effective is supersolidus liquid phase sintering, where the rapidly frozen microstructure forms liquid films on the grain boundaries to induce viscous flow densification. Pores retard grain growth unless there is a separation of the boundary from the pore, leaving the pores isolated inside the grains. Grain growth reduces the system energy by decreasing the total grain boundary energy. In some worse situations, pores coarsen due to the expansion of the gas in the pores. ${ }^{30}$ As the temperature is increased, the rate amount of liquid and transport rate increase. The higher sintering temperature increases UTS and elongation, but a reverse effect is found on density, TRS and hardness, as shown in Table 4. Sintering temperature influences dominate hardness, UTS and elongation and has a moderate role with respect to density, as shown in Fig. 6 (note that the elongation is the most sensitive to heating rate, a factor often associated with phase transformations, such as in transient liquid phase sintering. However, this effect was not examined in this study).

\section{Holding time effect}

The degree of sintering is improved with increasing sintering time and temperature. In comparison, the influence of temperature is significantly greater since the temperature appears in an exponential form. Like the sintering temperature, the longer holding time increases UTS and elongation, but a reverse effect is found on density, TRS and hardness, as shown in Table 4. Holding time predominantly influences mostly on hardness and UTS and moderately on density and elongation but negligible on TRS, as shown in Fig. 6.

\section{Heating rate effects}

According to Swinkels and Ashby, ${ }^{31}$ pore reductions and grain refinement will occur when the heating rate is increased. This is due to the reduction in driving force for the densification mechanism. In general, a lower heating rate will increase the thermal stresses because the heat transfer of a porous material is lower than on nonporous materials. The faster heating rate increases all properties, including sinter density, hardness, UTS and elongation, as shown in Table 4. Heating rate influences dominate density, hardness, UTS and elongation, with only a moderate effect on TRS, as shown in Fig. 6.

\section{Die compaction pressure effect}

Compaction pressure is the most influential parameter on the sintered density, and the highest compaction pressure yields the highest sintered density. The higher die compaction pressure increases all properties including sinter density, TRS, hardness, UTS and elongation, as shown in Table 4. Die compaction pressure influences TRS and moderately has a role on density, hardness and elongation, but is not important to UTS, as shown in Fig. 6 .

\section{Microstructure}

Figure 7 provides an overview of the microstructure variation resulting from the orthogonal array design of experiments. Sintered microstructure variations are most evident in the size and number of pores, especially for 
the Al-6061 compacted at $550 \mathrm{MPa}$ and sintered at either 630 or $650^{\circ} \mathrm{C}$ (Experiments 5 and 9). In the case of the lowest sintering temperature (Experiments 1-3), the general sense is poor bonding between the particles. With the combination of a low compaction pressure and low sintering temperature, the pore shape is irregular (for example, Experiment 2). When the sintering temperature increases from 610 to $650^{\circ} \mathrm{C}$, the porosity decreased. Other variations include the sintered grain size, which tends to increase with sintered density and is associated with a higher sintering temperature (Experiments 7-9). Mass transport along the grain boundaries provides a primary densification process, especially as the onset of liquid formation occurs along segregated regions.

\section{Optimum sintering conditions}

Based on this partial factorial analysis, optimum conditions can be extracted over the study range for any of the sintered properties. Obviously, longer sintering times, higher green densities, higher sintering temperatures or other heating rates might further benefit the properties or property combinations. However, over the range of reasonable parameters examined in this study, the property development with processing conditions is fairly clear. As for the sintered density, transverse rupture strength and hardness, the most fruitful conditions come from a lower sintering temperature, shorter holding time, the fastest heating rate and the highest die compaction pressure. Unfortunately, these conditions might be useful for certain attributes, but with respect to tensile strength and fracture elongation, optimisation comes with the highest sintering temperature, the longest holding time, the slowest heating rate and the highest die compaction pressure. Further consideration would have to be given to distortion and dimensional control, which might find yet another optimal combination. Clearly, for this alloy, the object function (e.g. hardness or strength) leads to a different combination of parameters for optimisation, so processing would need to be tuned to the most important properties.

\section{Conclusion}

The optimum condition for density and properties of a rapidly solidified Al-6061 powder was established using the Taguchi method. The ANOVA analysis showed that compaction pressure and all of the sintering factors greatly influenced the sintered density. The optimum sintering conditions for density corresponded to the highest compaction pressure, the lowest sintering temperature, the slowest heating rate and the shortest hold time, and this is similar for TRS and hardness. However, the highest sintering temperature, the longest holding time, the slowest heating rate and the highest die compaction pressure were associated with improved UTS and elongation.

\section{References}

1. D. G. White: Int. J. Powder Metall., 1999, 35, (5), 25-29.

2. E. J. Lavernia and N. J. Grant: J. Mater. Sci., 1987, 22, 1521-1529.

3. R. N. Lumley: Metall. Mater. Trans A, 1999, 30A, 457.

4. K. Kondoh: Powder Metall., 2001, 44, 161.

5. J. M. Martin: Powder Metall., 2002, 45, 173.

6. R. N. Lumley: Scr. Mater., 1996, 35, 589.

7. D. P. Bishop, M. C. Chaturvedi, G. J. Kipouros and W. F. Caley: Adv. Powder Metall. Part. Mater., 1998, 2, (Part 9), 9-23.

8. D. P. Bishop, X. Y. Li, K. N. Tandon and W. F. Caley: Wear, 1998, 222, 84-92.

9. D. P. Bishop, G. J. Kipouros and W. F. Caley: J. Mater. Sci., 1997, 32, 2353-2358.

10. D. P. Bishop, J. R. Cahoon, M. C. Chaturvedi, G. J. Kipouros and W. F. Caley: J. Mater. Sci., 1998, 33, 3927-3934

11. J. M. Martin: Powder Metall., 2002, 45, 173

12. R. N. Lumley: Scr. Mater., 1996, 35, 589.

13. G. B. Schaffer: Mater. Chem. Phys., 2001, 67, 85.

14. G. B. Schaffer: Powder Metall., 1999, 42, 219.

15. T. B. Sercombe: Acta Mater., 1999, 47, 689.

16. T. B. Sercombe: Mater. Sci. Eng. A, 2003, A341, 163.

17. W. H. Hunt, Jr: Int. J. Powder Metall., 2009, 36, (6), 51.

18. P. J. Ross: 'Taguchi techniques for quality engineering'; 1989, New York, McGraw-Hill.

19. R. G. Iacocca and R. M German: Powder Technol., 1999, 102, $253-$ 265 .

20. I. J. Polmear: 'Light alloys', 124-127; 1995, London, Arnold.

21. J. M. Papazian: Metall. Trans. A, 1988, 19A, 2945.

22. L. F. Mondolfo: 'Aluminum alloys: structure and properties', 245262; 1976, London, Butterworths.

23. H. J. Rack and R. W. Krenzer: Metall. Trans. A, 1977, 8A, 335.

24. K. Kondoh, A. Kimura and R. Watanable: Powder Metall., 2001, 44, (2), 161 .

25. G. B. Schaffer, B. J. Hall, S. J. Bonner, S. H. Huo and T. B. Secombe: Acta Mater., 2006, 54, 131-138.

26. J. H. Dudas and C. B. Thompson: 'Modern developments in powder metallurgy', Vol. 5, 19; 1971, New York, Plenum Press.

27. H. E. Exner: Met. Sci., 1982, 16, 451-455.

28. D. L Johnson: 'Solid state sintering', in 'Encyclopedia of material science and engineering', (ed. M. B. Bever), Vol. 6, 4520-4525; 1986, Oxford, Pergamon Press.

29. W. J. Huppmann: Int. J. Powder Metall. Powder Technol., 1985, 2, (3) $183-191$.

30. R. M. German: 'Powder injection molding'; 1990, Princeton, NJ, MPIF.

31. F. B. Swinkels and M. F. Ashby: 'Second report on sintering diagrams', Acta Metall., 1981, 29, 259-281. 